\title{
Incidence and Clinical Significance of Cardiac Murmur in Neonates in a Tertiary Hospital
}

\author{
Md. Belal Hossain ${ }^{1}$, Md. Sanaul Haque Mia ${ }^{2}$, Md. Rustam $\mathrm{Ali}^{3}$, Shirajee Nazmul Hasnain ${ }^{4}$ \\ Md. Ismail Hossain Khan ${ }^{5}$, Firoz Ahmed ${ }^{6}$, Mst. Musarrat Sultana ${ }^{7}$
}

\begin{abstract}
Background: Congenital cardiac defect is the major cause of mortality and morbidity in our country but maximum cases are undetected due to lack of skill, shortage of man power, modern equipment in peripheral hospitals. But simply observing murmur can give us the clue for underlying congenital heart diseases. Objectives: The purpose of this study is to determine the incidence and clinical significance of cardiac murmur in neonates in a tertiary level hospital in Rajshahi. Methods: This cross-sectional descriptive study was done in neonates (age $\leq 28$ days) in Rajshahi Medical College Hospital from January 2014 to December 2015. Results: during this study period total $\mathbf{4 1 2 0}$ neonates were admitted in neonatal ward and only $\mathbf{5 2}$ cases were presented with cardiac murmur clinically. Incidence rate of murmur was $1.26 \%$. Among 52 cases 40 cases were having pathological murmur and 12 cases were having innocent murmur. After doing echocardiogram 34 cases were showing structural cardiac defect out of 40 pathological murmur and 4 cases were showing structural cardiac defect out of 12 innocent murmur. Total cases of structural cardiac defect (congenital heart disease) were $38(34+4)$. So, incidence of congenital heart disease was 9.221000 live births. Conclusion: Congenital cardiac defect is the major cause of mortality and morbidity in our country but maximum cases are undetected during neonatal period but simply observing murmur can give us the clue for underlying congenital heart diseases in $73.08 \%$ cases ( 38 were congenital heart disease out of 52 cases). If congenital heart disease is early detected and properly managed many valuable lives of neonates can be saved and their growth and development will be smooth.
\end{abstract}

Key words: murmur, congenital heart diseases, ASD, VSD, TOF

TAJ 2017; 30: No-2: 54-59

\section{Introduction}

Congenital heart disease (CHD) is one of the most common congenital malformations affecting $6 / 1000$ live births. They account for $10 \%$ of infant deaths and about $50 \%$ of deaths from malformations. ${ }^{1}$ If a murmur is heard during neonatal examination there is a $54 \%$ chance of there being an underlying cardiac malformation. ${ }^{2}$ A cardiac murmur may be the first sign of a serious structural cardiac disease, especially in the neonate. Many studies have been carried out worldwide, showing incidence of CHD in different parts of the world is 5-10/1000 live birth. But in Bangladesh, a mere study was done in this respect.

\footnotetext{
1 Junior Consultant (Paediatrics), Rajshahi Medical College Hospital, Rajshahi.

2 Professor and Head, Department of Paediatrics, Rajshahi Medical College, Rajshahi.

${ }^{3}$ Registrar, Department of Paediatrics, Rajshahi Medical College Hospital, Rajshahi.

${ }^{4}$ Assistant Professor (ex), Department of Paediatrics, Rajshahi Medical College.

5 Junior Consultant (Paediatrics), Mohonpur UHC, Rajshahi.

${ }^{6}$ Junior Consultant (Paediatrics), UHC, Kushtia Sadar, Kushtia.

${ }^{7}$ Junior Consultant (Paediatrics), Gurudaspur UHC, Natore.
} 
A cross sectional study found that the prevalence rate of CHD in neonates was about 7.8/1000 live births. ${ }^{3}$ In a study Lardhi found that the incidence rate of neonatal murmur was $1.37 \%$ (87 out of 6333) among which $42.5 \%$ (37 out of 87 ) had a structural cardiac malformation. ${ }^{4}$ Beebe S.A et al. found that $57 \%$ of neonates dying from cardiovascular malformations after discharge from hospital had had a murmur before discharge. ${ }^{5}$ Therefore this study was taken to detect cardiac murmur in neonate (within 28 days of life) which helps us to seek appropriate management in very early life of our children to smooth their growth and development.

\section{Materials and Methods}

This was a cross-sectional descriptive study, conducted in the neonatal unit of Rajshahi Medical College Hospital. Study period was 2 years from January 2014 to December 2015. Total 4120 neonates were admitted in neonatal ward during this study period. Among them 52 neonates had cardiac murmur and fulfilled the selection criteria (inclusion and exclusion criteria). Inclusion criteria: age-0-28 days of life and presence of murmur. Exclusion criteria: age- more than 28 days, neonates having emergency surgical abnormalities, syndromic babies and diagnosed cases of congenital heart disease. All mothers of selected babies were interviewed and filled up a prescribed questionnaire. Few relevant information was taken which includes: age, sex, history of present complaints, physical findings including murmur. All the findings and investigation reports were recorded and analyzed.

\section{Results}

We examined total 4120 neonates during this study period among them only 52 (1.26\%) neonates were presented with cardiac murmur. So, incidence rate of cardiac murmur in neonates was $1.26 \%$. Most of the neonates having murmur presented within $1^{\text {st }}$ week of life (46.15\%). Mean age of all the neonates was $(11.81 \pm 8.49)$ days, ranging from 1 day to 28 days. Murmur was detected more in the male $(30=58 \%)$ than female baby $(22=42 \%)$. Male: female ratio was 1.36:1. Preterm babies ( $<37$ weeks of gestation) were more prone to develop cardiac murmur (61. 54\%).
Maximum neonates who were presented with murmur were the offspring of non-consanguineous parents $(48=92.31 \%)$ and came from low socioeconomic family $(30=57.70 \%)$. Physical examination revealed tachycardia and tachypnea in the most of the patients. A major portion of the patients presented with feature of heart failure like- hepatomegaly, forehead sweating, crepitation etc. All murmurs were systolic in nature without radiation. Most of the murmur was best heard at the pulmonary area (34.61\%) and at the left $3^{\text {rd }}$ and $4^{\text {th }}$ intercostal area adjacent to sternum. X-Ray of $21.15 \%$ neonates revealed normal findings but 78.85\% neonates presented with abnormal X-Ray findings- cardiomegaly (30.77\%), feature of pneumonia (32.69\%), plethoric (40.38\%) and oligaemic lung field (11.54\%). About 26.92\% (14 out of 52 cases) neonate's echocardiogram finding was normal. 23.08\% (12 out of 52 cases) presented with VSD and $21.15 \%$ (11 out of 52 cases) neonates presented with ASD. PDA detected in $11.54 \%$ (06 out of 52 neonates) cases and TOF in $7.69 \%$ (4 out of 52 neonates) cases. Among the 52 cases 40 cases (77\%) were having significant (pathological) murmur and 12 cases (23\%) were having innocent murmur. Echocardiogram detected 14 cases $(26.92 \%)$ as normal cardiac anatomy and 38 cases (73.08\%) with cardiac defect. Among the innocent murmur echocardiogram detected cardiac defect in 4 cases (4 out of 12 cases) that means 33.33\% neonates of innocent murmur having cardiac defect and echocardiogram also detected cardiac defect in 34 cases out of 40 cases of pathological murmur that means 85\% neonates of pathological murmur having cardiac defect. Echocardiogram detected 38 patients having structural heart defect among them congenital cyanotic heart disease was 08 $(21.05 \%)$ and acyanotic heart disease was 30 (78.95\%).

In our study we found statistically significant relationship between clinically suspected murmurs and echocardiogram findings ( $p$ value is 0.001 ) that means clinical suspicion was able to differentiate between innocent murmur due to normal heart and significant murmur due to structural heart defect. So, we should carefully 
examine and investigate all neonates who presented with cardiac murmur to evaluate structural cardiac defect. After sensitivity, specificity predictive value and validity test, the sensitivity was $89 \%$, specificity was $57 \%$, positive predictive value was $85 \%$, negative predictive value was $66.66 \%$ and accuracy or validity was $80.76 \%$. Here specificity and negative predictive value rate is $57 \%$ and $66.66 \%$ respectively. These rates are lower than the expected value. It may be due to the lack of my skill, experience and doing echocardiogram from various investigation centers. [According to Robertson's Text Book of Neonatology $4^{\text {th }}$ edition- if physical examination is done by a pediatric cardiologist accuracy will be higher than a trainee doctor in case of innocent murmur. Even an adult cardiologist may misclassify up to $33 \%$ innocent murmur. ${ }^{6}$

Table-1: Presenting features $(\mathrm{N}=52)$

\begin{tabular}{|l|l|l|}
\hline Features & $\begin{array}{l}\text { No. } \\
\text { neonates }\end{array}$ & Percentage \\
\hline Murmur & 52 & $100 \%$ \\
\hline Fever & 24 & $46.15 \%$ \\
\hline Cyanosis & 08 & $15.38 \%$ \\
\hline Pallor & 12 & $23.08 \%$ \\
\hline Plethora & 04 & $7.69 \%$ \\
\hline $\begin{array}{l}\text { Respiratory } \\
\text { distress }\end{array}$ & 37 & $71.15 \%$ \\
\hline Hepatomegaly & 26 & $50.00 \%$ \\
\hline Splenomegaly & 03 & $5.77 \%$ \\
\hline Hypotonia & 02 & $3.85 \%$ \\
\hline Forehead swelling & 14 & $26.92 \%$ \\
\hline $\begin{array}{l}\text { Tachycardia } \\
\text { (>140/min) }\end{array}$ & 50 & $100 \%$ \\
\hline $\begin{array}{l}\text { Tachypnoea } \\
\text { (>60/min) }\end{array}$ & 39 & $75.00 \%$ \\
\hline Crepitation & 26 & $50.00 \%$ \\
\hline
\end{tabular}

Table- 2: Precordium examination findings $(\mathrm{N}=52)$

\begin{tabular}{|l|l|l|}
\hline Findings & Number & Percentage \\
\hline Apex beat in $4^{\text {th }}$ left ICS & 42 & $80.77 \%$ \\
\hline Apex beat in $5^{\text {th }}$ left ICS & 10 & $19.23 \%$ \\
\hline Thrill & 18 & $34.61 \%$ \\
\hline Left parasternal heave & 03 & $5.77 \%$ \\
\hline Palpable $\mathrm{P}_{2}$ & 00 & $00 \%$ \\
\hline Systolic murmur & 46 & $88.46 \%$ \\
\hline Diastolic murmur & 00 & $00 \%$ \\
\hline Continuous murmur & 06 & 11.54 \\
\hline Radiation & 00 & $00 \%$ \\
\hline
\end{tabular}

Table-3: Echocardiogram finding

\begin{tabular}{|l|l|l|}
\hline Findings & $\begin{array}{l}\text { No of } \\
\text { patient }\end{array}$ & Percentage \\
\hline Normal findings & 14 & $26.92 \%$ \\
\hline VSD & 12 & $23.08 \%$ \\
\hline ASD cushion & 11 & $21.15 \%$ \\
\hline PDA & 06 & $11.54 \%$ \\
\hline $\begin{array}{l}\text { Endocardial } \\
\text { defect }\end{array}$ & 4 & $1.92 \%$ \\
\hline TOF with & 1 & $1.92 \%$ \\
\hline Severe PS with VSD & 2 & $3.85 \%$ \\
\hline $\begin{array}{l}\text { Tricuspid atresia } \\
\text { Single ventricle }\end{array}$ & 1 & $1.92 \%$ \\
\hline TGA+ASD & 52 & $100 \%$ \\
\hline Total & \multicolumn{2}{|l}{} \\
\hline
\end{tabular}

Fig-1: Distribution of significant and innocent murmur

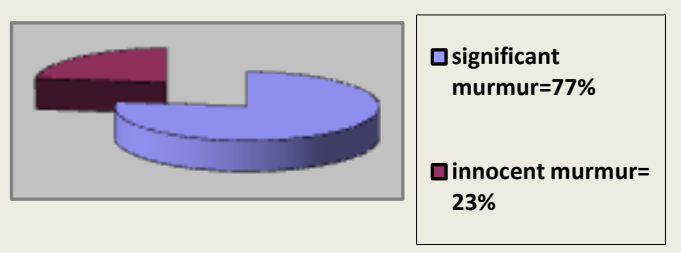


Table 4: Relation between clinically suspected murmur and echocardiogram finding $(\mathrm{N}=52)$

\begin{tabular}{|l|c|c|c|l|}
\hline $\begin{array}{l}\text { Clinically } \\
\text { suspected } \\
\text { murmur }\end{array}$ & \multirow{2}{*}{$\begin{array}{l}\text { Total } \\
\text { N\%) }\end{array}$} & \multicolumn{2}{|c|}{$\begin{array}{c}\text { Echocardiogram } \\
\text { finding }\end{array}$} & \multirow{2}{*}{$\begin{array}{l}\text { value } \\
*\end{array}$} \\
\cline { 2 - 4 } & $\begin{array}{c}\text { Structur } \\
\text { al heart } \\
\text { defect }\end{array}$ & $\begin{array}{c}\text { Normal } \\
\text { heart }\end{array}$ & \multirow{2}{*}{0.001} \\
\hline $\begin{array}{l}\text { Significan } \\
\mathrm{t}\end{array}$ & $\begin{array}{c}40 \\
(76.92 \%)\end{array}$ & $\begin{array}{c}34 \\
(65.38 \\
\%)\end{array}$ & $\begin{array}{c}06 \\
(11.54 \%)\end{array}$ & \\
\hline Innocent & $\begin{array}{c}12 \\
(23.08 \%)\end{array}$ & $\begin{array}{c}04 \\
(7.69 \%)\end{array}$ & $\begin{array}{c}08 \\
(15.38 \%)\end{array}$ & \\
\hline Total & $\begin{array}{c}52 \\
(100 \%)\end{array}$ & $\begin{array}{c}38 \\
(73.07 \\
\%)\end{array}$ & $\begin{array}{c}14 \\
(26.93 \%)\end{array}$ & \\
& & & \\
\hline
\end{tabular}

Flow diagram-1: Reclassification of murmur after echocardiogram

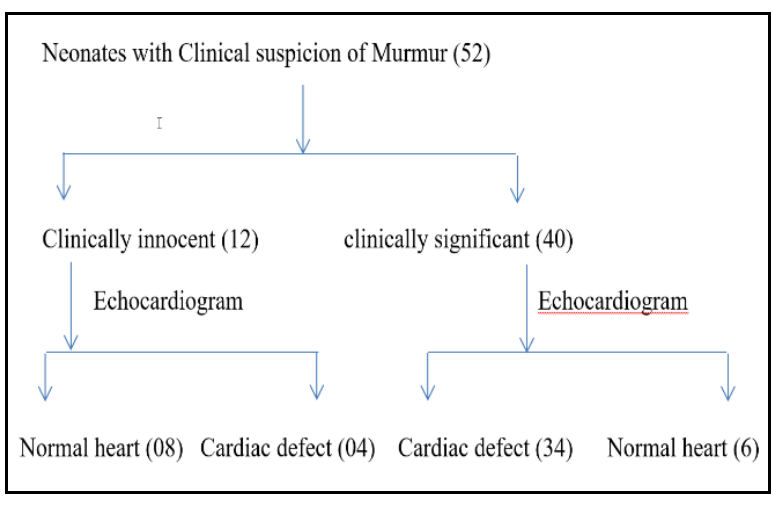

\section{Discussion}

There is a popular believe that murmur in neonatal period has no importance, it is a physiological phenomenon. ${ }^{7}$ But it is not true at all. Murmur in neonatal period may be the first sign of underlying serious structural cardiac defect. About 50\% neonates revealed congenital cardiac defect that were presented with murmur. We should carefully reveal these cardiac murmurs to prevent the unwanted death of children because $57 \%$ of neonates would die from cardiovascular malformation after discharge from hospital that had a murmur before discharge.

Maximum neonates did not present any feature of congenital heart diseases although they having structural cardiac defect. They were remaining asymptomatic. Detection of a murmur during physical examination may guide us to detect the heart problem before the development of life threatening complications. About half of these murmurs in the neonates are due to an underlying cardiovascular malformations. ${ }^{8}$

In our study we had found the incidence rate of cardiac murmur was $1.26 \%$. Till date, numerous studies were done in worldwide describing the incidence of cardiac murmur in the neonates varies from $0.6 \%$ to $77.4 \%$. Ainsworth et al. had shown in their study that the incidence of murmur in neonates was $0.6 \%$. In another study Lardhi had found that the incidence of cardiac murmur in neonates was $1.37 \%$. These variations may be due to the examiners' skills and experience, the timing and frequency of examination; the conditions under which examination took place and the size of population studied.

Cardiac murmur includes both pathological and innocent. In our study pathological murmur was $76.92 \%$ (40 out of 52) and innocent murmur was $23.08 \%$ (12 out of 52). Rein et al. found that murmur in $76 \%$ cases was due to underlying structural cardiac defect and murmur of $24 \%$ cases was innocent. ${ }^{9}$

Our study revealed that $58 \%$ babies (30 out of 52) were male and $42 \%$ babies (22 out of 52) were female who presented with murmur. Male female ratio was $1.36: 1$. Sharmin et al. found the very close result in their study in Rajshahi Medical College Hospital. In their study male female ratio was $1.30: 1 .^{10}$ Hussain $M$ et al. also found the similar result in Dhaka Shishu Hospital. They found the male female ratio was 1.43:1. ${ }^{11}$

The incidence of congenital heart diseases in our study was 9.7/1000 live birth which was more close to the result of many studies. But the incidence of congenital heart diseases (CHD) varies from about 4/1000 live birth to 50/1000 live births. ${ }^{12}$ This wide variation was primarily due to variations in the ability to detect trivial cardiac lesions. ${ }^{13}$ But in our country there was a very few significant study was done till now.

Our study had shown that acyanotic congenital heart diseases were more common than cyanotic congenital heart diseases. In our study, the rate of 
acyanotic heart diseases was $78.95 \%$ (30 out of 52 ) and cyanotic heart diseases was $21.05 \%$ (8 out of 52). ManzoorHussain et al. had shown that the rate was $78.5 \%$ and $21.5 \%$ respectively. ${ }^{14}$ Rahman et al. had found $84.4 \%$ acyanotic CHD in their study. ${ }^{15}$ Similar result was found by Begum NNF et al. ${ }^{16}$

In our study, the most frequently diagnosed acyanotic heart disease was VSD (23.08\%-12 out of 52) then ASD (21.15\%-11 out of 52) and PDA (11.54\%-6 out of 52) which were similar to other study results. Hussain et al. had found that incidence of VSD was $32.70 \%$ then ASD (incidence was $21.20 \%) .{ }^{11}$ In another study which was done in Dhaka Shishu Hospital had shown that VSD was the commonest acyanotic lesion and TOF was the most common cyanotic lesion ${ }^{14}$. But this differs from Rahmanet $\mathrm{al}^{15}$, Fatema et $\mathrm{al}^{16}$ and Siddique et al. ${ }^{17}$ They had found that ASD was the commonest lesion followed by VSD.

All the available data regarding cardiac murmur and congenital heart disease in neonates are from developed countries. A very few publications are available from Indian subcontinent. ${ }^{18,19}$ So, we should study more regarding this aspect.

In our study we were able to detect about $73 \%$ cases of cardiac defect by detecting murmur clinically (38 out of 52 cases). Without detecting murmur routine neonatal examination cannot identify congenital heart disease in maximum cases. ${ }^{20}$ But, with very carefully hearing murmur and doing an echocardiography we can detect underlying cardiac malformation in neonates up to $86 \%$ cases. Hoque et al. $^{21}$ and Moss et al. ${ }^{22}$ had shown in their study that proper and careful echocardiography can detect underlying structural cardiac lesion up to $70 \%$ of clinically suspected cases with murmur. So, we should be very careful during detection of cardiac murmur in neonates.

\section{Conclusion}

Early diagnosis and timely referral to higher center can significantly improve the outcome of congenital heart disease. Examination of precordium of every neonate by a trained physician can help in the early diagnosis of congenital heart disease.

\section{References}

1. Abu-Harb M, Wyllie J, Hey E, Richmond S, Wren C. Presentation of obstructive left heart malformation in infancy. Arch Dis Child Fatal Neonatal.1994;Ed; 71:F179-83.

2. Sean B Ainsworth, Jonathan P Wyllie, Christopher Wren. Prevalence and clinical significance of cardiac murmurs in neonates. Arch Dis Child Fetal Neonatal.1999;80: 43-45.

3. Islam MN, Hossain MA, Khaleque MA, Das MK, Khan MRH, Bari MS, Bhuiyan MKJ. Prevalence of Congenital Heart Disease in Neonate in a Tertiary Level Hospital. Nepal Journal of Medical sciences 2013;2 (2): 91-5.

4. Amer Abdullah Lardhi. Prevalence and clinical significance of heart murmurs detected in routine neonatal examination. Journal of the Saudi Heart Association. 2010; 22, 25-27.

5. Beebe SA, Britton JR, Britton HL, Fan P, Jepson B. Neonatal mortality and length of newborn hospital stay. Pediatrics. 1996;vol-98: 231-5

6. Kopes-Kerr CP, Horton. hears a Who but no murmurs - does it matter? Family Practice. 2002;19: 422-25.

7. Hossain M H, Hasan MNA, Shirin M, Mamun M A A, Hossain M D, Clinical Significance of Cardiac Murmur in Neonate, Bangladesh j child health. 2010;34 (2):56-61

8. Wren C, Richmond S, Donaldson L. Presentation of congenital heart disease in infancy: implications for routine examination. Arch Dis Child Fetal Neonatal. 1999; 80: 49-53.

9. Rein AJT, Omophorion SI. Significance of a cardiac murmur as the sole clinical sign in the newborn. Clin Pediatrics; ( 2000), vol-39: page-511-520

10. Sharmin L S, Haque M A, Bari M I, Ali M A. Pattern and Clinical Profile of Congenital Heart Disease in A Teaching Hospital, TAJ.June 2008; 21(1): 58-62

11. Hussain M, Hossain M, Amin SK, Molla MR. Pattern of congenital heart disease in Dhaka Shishu Hospital. D S (Child) H J; 1992; 8:42-46,

12. Hoffman J.I., Kaplan S. The incidence of congenital heart disease. J Am Cardiol. 2002; 39:1890-1900.

13. Roguin N, Du Z D, Barak M., Nasser N, Hershkowitz S. High prevalence of muscular ventricular septal defect in neonates. J Am Coll Cardiol. 1995, 26: 1545-1548.

14. Hussain M, Tahura S, Sayeed M A, Rahman M A, Rahman M A, Kar A K. Bangladesh j child health; 2010, 34 (2): 51-55 
15. Rahman S, Ahmed MN, Rahmatullah KHI, Alam MS, The incidence of congenital heart diseases diagnosed by non- invasive technique- ten years study in Bangladesh. Ds (child), HJ. 1992;8: 5-15

16. Begum NNF. Atrial septal defect: analysis of 393 cases. Chest and heart journal; 2003;27(1), 31-35

17. Siddique FM, Kamal SMM, Huq KMHSS, Clinical presentation of congenital heart disease in hospitalized patients. Bangladesh heart journal. 1989;4:13-17

18. Poddar B, Basu S, Approach to a child with a heart murmur. Indian J Pediatrics. 2004; 71: 63-66.

19. Bansal $M$, Jain $H$. Cardiac murmur in neonates. Indian Pediatric journal. 2005;42:97-98.
20. Richmond S. And Wren C - Early diagnosis of congenital heart disase. Semin Neonatol.2001;6:27-35.

21. Hoque MM, Begum JA, Jahan R, Chowdhury MA, $\mathrm{KA}$, Hussain M. Importance of cardiac murmur in diagnosing congenital heart disease in neonatal period. Bangladesh J Child Health. 2008;32:17-20

22. Moss S, Kitchiner DJ, Yoxall CW, Subhedar NV. Evaluation of echocardiography on the neonatal unit. Arch Dis Child Fetal Neonatal. 2003; 88:28791.

All corresponds to: Dr. Md. Belal Hossain Junior consultant (pediatrics) Department of pediatrics, Rajshahi Medical College Hospital, Rajshahi Email:dr.belal71@gmail.com 